\title{
Lotfi Zadeh - some personal memories
}

\author{
Eulalia Szmidt ${ }^{1,2}$ \\ ${ }^{1}$ Systems Research Institute Polish Academy of Sciences \\ Newelska 6, 01 - 447 Warsaw, Poland \\ e-mails: szmidteibspan.waw.pl \\ ${ }^{2}$ Warsaw School of Information Technology, \\ ul. Newelska 6, 01-447 Warsaw, Poland
}

I met Lotfi Zadeh for the first time during the IPMU Conference in Paris in 1986. I have just defended my Ph.D. thesis and was happy to see Prof Zadeh and many famous scientists. For the next ten years, I was working in a different area and had not a chance to see Prof. Zadeh. Then he visited our Institute. After his lecture, I approached him with other colleagues. He looked at me and called me by my name. I was completely surprised how it was possible to remember a name by somebody seen for not too long so many years ago. Anyway, it was possible. I am full of admiration for his memory (among others (-)). Next, I had many opportunities to meet Prof. Zadeh during many conferences. He was always surrounded by lots of people and seemed to like it. Always very friendly and open for discussions.

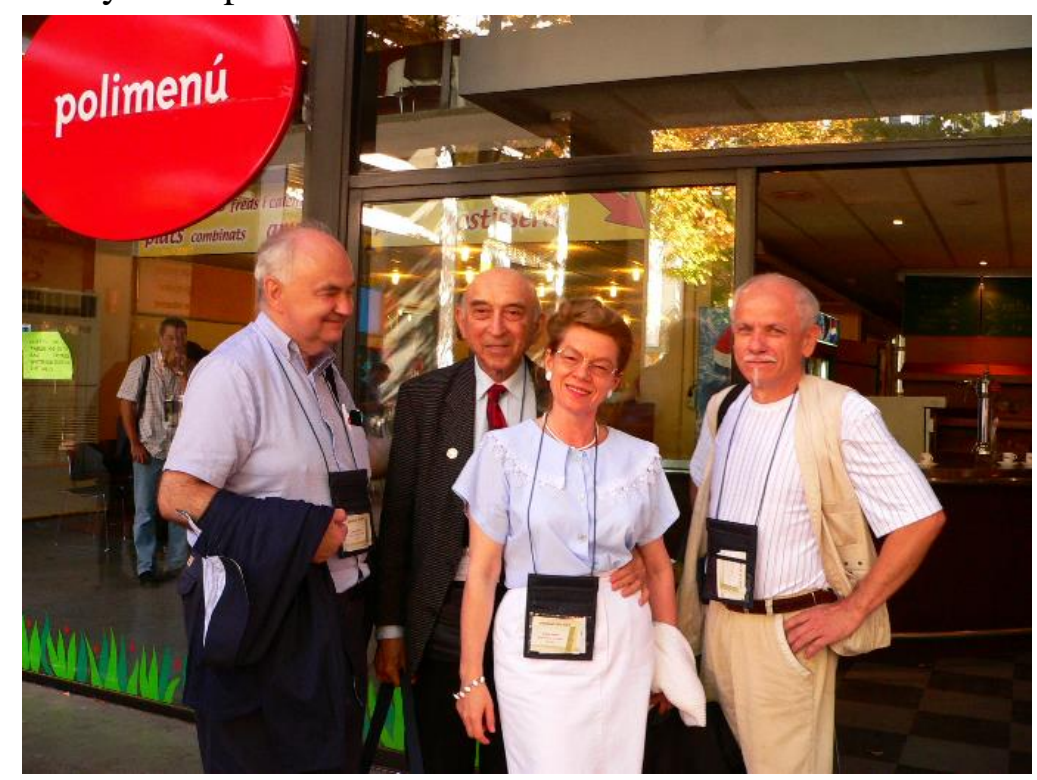




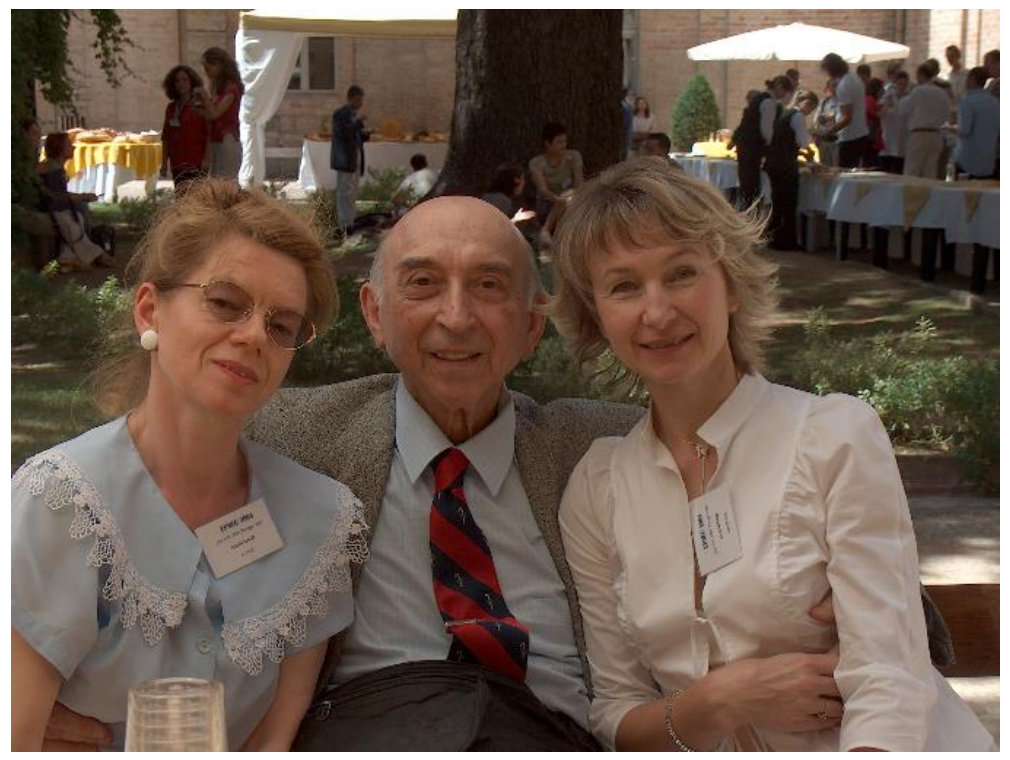

Figure 1. I had a pleasure to meet Lotfi Zadeh at many conferences

Prof. Zadeh was very supportive of each and everybody. He was famous, a sort of a movie star $(-)$ but at the same time, he did not intimidate people. Sometimes during somebody's presentation, he seemed not to listen but at the end, he was touching upon the kernel of the matter. After his lectures, he used to repeat: "do not hesitate to disagree with me".

Lotfi Zadeh was the author of (almost) all the main ideas in the field. Later the ideas were developed by others but the foundations were given by him. He built a huge social network, a whole community working on the problems pointed out by him. He was an unquestionable leader of the community.

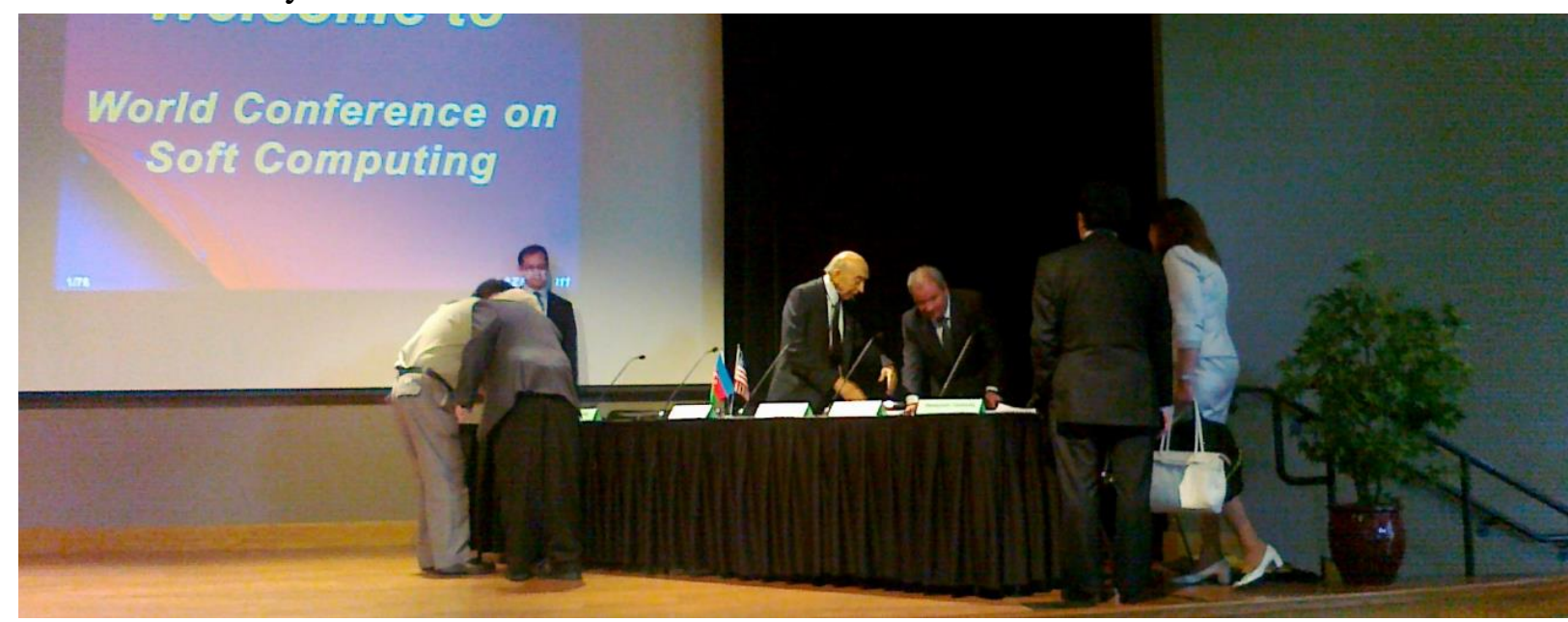

Figure 2. Lotfi Zdeh (left, behind a table), San Francisco 2011

He was a tireless traveler participating in plenty of conferences. He did not like to say "goodbye" and was sometimes just disappearing suddenly in the middle of a conference but we were sure that the next meeting is ahead.

He was talking not once about his difficulties and the severe critique of the idea of fuzzy set theory and fuzzy logic. He was telling that it is necessary to have thick skin when introducing new ideas. Another of Lotfi's thoughts which helped many of us (including me when the 
Intuitionistic Fuzzy Sets (IFSs) introduced by Krassimir Atanassov were not welcome with enthusiasm) was: "whatever they say take it as a compliment". By the way, Lotfi liked the idea of IFSs.

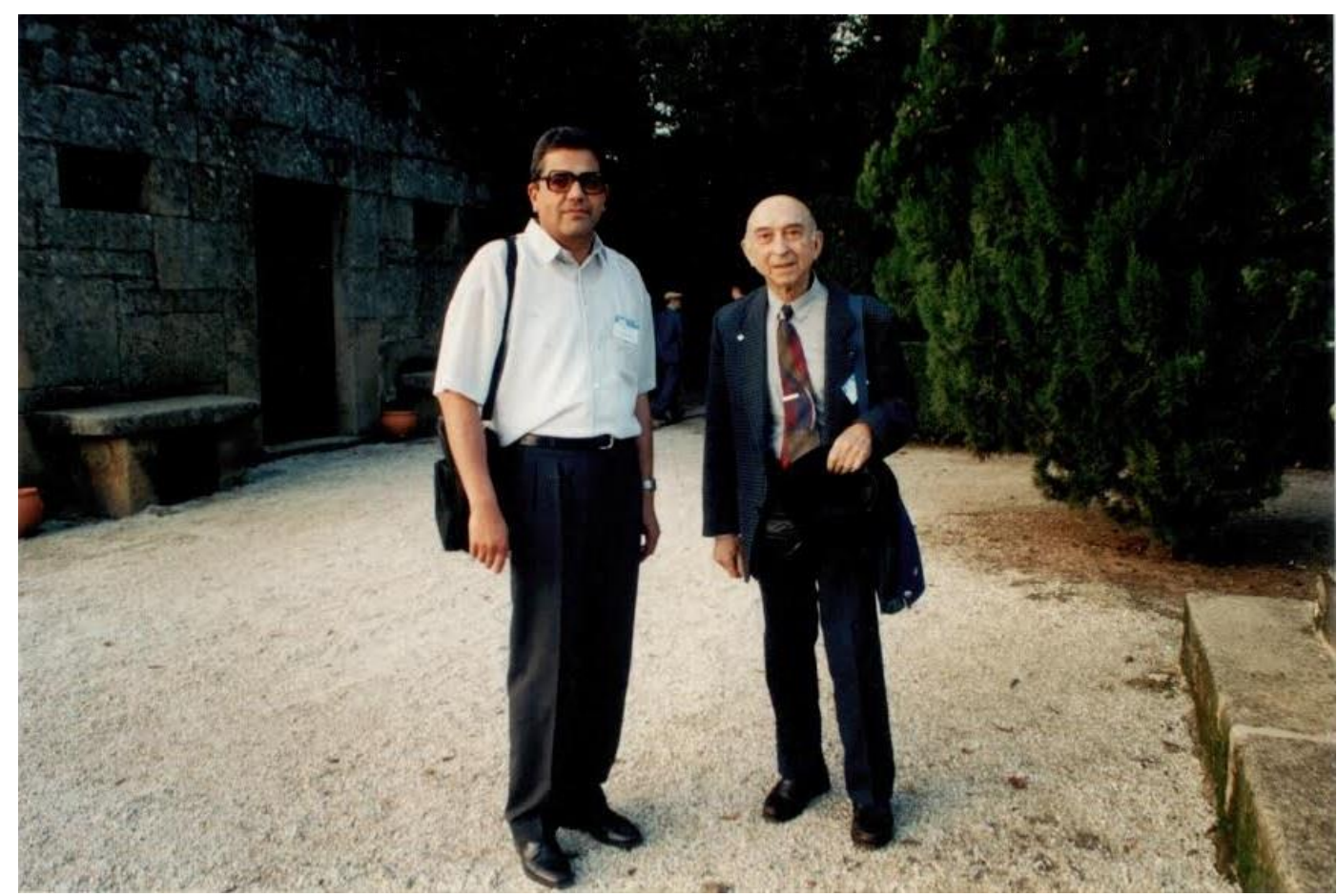

Figure 3. Lotfi Zadeh (right) and Krassimir Atanassov (left)

Lotfi was interested not only in scientific problems but also was always ready to listen to our private ups and downs. He was also very interested in world problems. Knowing perfectly Russian he was following everyday news broadcasted both from the US and Russia having this way insight into important problems from different points of view.

Portrait photography was his hobby. One day he sent us a whole collection of excellent portraits of interesting people. A portrait of Harry Truman, US senators, famous pianists, actors, not to speak about many well-known scientists. He met all of them during his travels or made the photos at his home studio.

Lotfi's wife Fay was all his adult life at his side. She was a frequent companion of his travels. The travels were an inspiration for her to write a book: "My Life and Travels With the Father of Fuzzy Logic". It is a very interesting source of his private life, a story full of humor, and sparkling wit. 

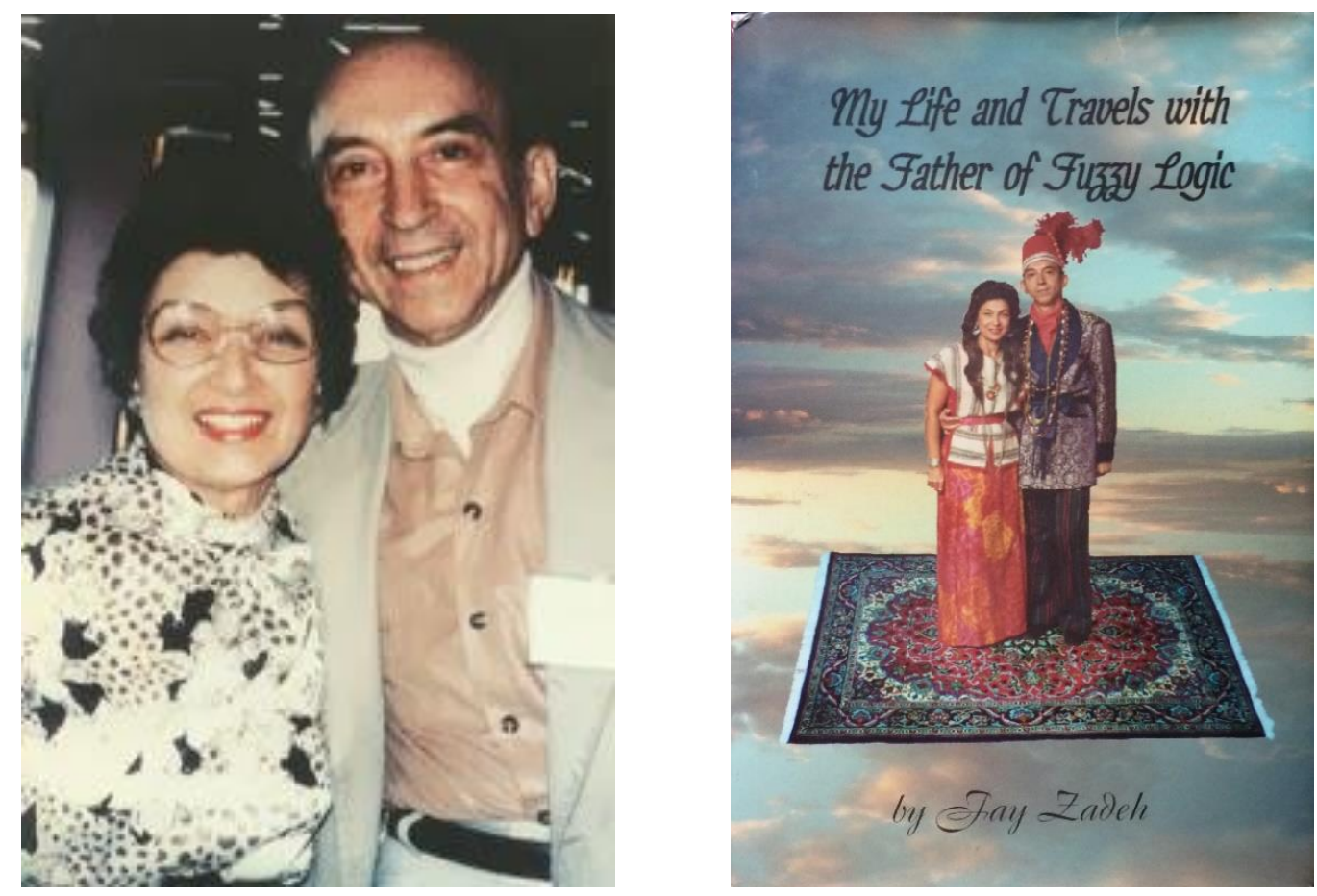

Figure 5. Fay and Lotfi Zadeh (left); the cover of the book by Fay Zadeh (right)

Lotfi Zadeh was an exceptional, gifted person, a true leader. His leadership was not by power or dominance but the opposite - he was very calm, polite, inspiring, and supportive. He was interesting and interested. All the meetings, all the conferences with him had a special unforgettable charm. 